\title{
CARACTERÍSTICAS DOS CURSOS SUPERIORES DE TECNOLOGIA E BACHARELADO EM SECRETARIADO: UM ESTUDO COM BASE NA INTERPRETAÇÃO DAS DIRETRIZES CURRICULARES.
}

\section{CHARACTERISTICS OF TECHNOLOGICAL AND BACHELOR'S DEGREE IN THE SECRETARIAT COURSES: A STUDY BASED ON THE INTERPRETATION OF THE CURRICULUM POLICIES.}

\section{Vanderleia Stece}

Mestre em Educação pela Universidade Tuiuti do Paraná - UTP

Professora e coordenadora do Curso Superior de Tecnologia em Secretariado do Centro Universitário Internacional UNINTER

E-mail: vanderleia.o@grupouninter.com.br (Brasil)

\section{Edilaine Cegan}

Mestre em Administração pela Universidade Positivo

Professora no Centro Universitário Internacional - UNINTER

E-mail: edilaine23@hotmail.com (Brasil)

\section{Thereza Cristina Souza Lima}

Doutora em Estudos Linguísticos pela Universidade Estadual Paulista Júlio de Mesquita Filho UNESP

Professora no Centro Universitário Internacional - UNINTER

E-mail: tcslcristina@gmail.com (Brasil)

\section{Ana Maria Boguslawski}

Graduação em Secretariado Executivo pela Pontifícia Universidade Católica do Paraná - PUC/PR Professora no Instituto Federal de Educação do Paraná - IFPR

E-mail: ana.bo@hotmail.com (Brasil) 


\title{
CARACTERÍSTICAS DOS CURSOS SUPERIORES DE TECNOLOGIA E \\ BACHARELADO EM SECRETARIADO: UM ESTUDO COM BASE NA \\ INTERPRETAÇÃO DAS DIRETRIZES CURRICULARES.
}

\begin{abstract}
RESUMO
Embora as atividades de secretariado já existam de longa data, a regulamentação da profissão ainda é recente, pois data de 30/09/1985. Devido à evolução da profissão e o surgimento da formação tecnológica de nível superior, muitas dúvidas são originadas quanto à formação e atuação dos profissionais formados nos cursos de tecnologia e bacharelado. Nesse sentido, este estudo busca apresentar as possíveis diferenças existentes na formação e atuação dos profissionais formados nos cursos superiores de tecnologia e bacharelado em Secretariado. Como metodologia, a pesquisa qualitativa embasou o estudo, e o principal instrumento utilizado foi a análise documental dos seguintes documentos: lei de regulamentação da profissão (Lei 7.377, de 30/09/85 e Lei 9.261, de 10/01/96); Diretrizes Curriculares Nacionais Gerais para a organização e o funcionamento dos cursos superiores de tecnologia (Resolução CNE/CP 3, de 18 de dezembro de 2002), Catálogo Nacional de Cursos Superiores de Tecnologia e Diretrizes Curriculares Nacionais para o curso de Secretariado Executivo (Resolução CNE/CES n. 3/2005, de 23 de junho de 2005. A pesquisa apontou que as principais diferenças estão relacionadas à carga horária, à oferta de idiomas, e à nomenclatura dos cursos. Demonstra também que a lei de regulamentação da profissão, não prevendo as diferenças existentes entre os dois graus de formação, contribui para o surgimento de dúvidas, principalmente sobre a atuação desses profissionais, uma vez que ambos são considerados Secretários Executivos.
\end{abstract}

Palavras-chave: Cursos Superiores; Tecnologia; Bacharelado; Secretariado; Diretrizes.

Revista de Gestão e Secretariado - GeSec, São Paulo, v. 5, n. 1, p 62-81, jan./abr. 2014. 


\title{
CHARACTERISTICS OF TECHNOLOGICAL AND BACHELOR'S DEGREE IN THE SECRETARIAT COURSES: A STUDY BASED ON THE INTERPRETATION OF THE CURRICULUM POLICIES.
}

\begin{abstract}
Although the secretary activities have existed for a long time, the profession regulation is still recent, as it dates of September 30 th, 1985. Due to the professional evolution and to the raise of technology, many doubts have risen, concerning qualification and professional performance of the technological and undergraduate program. Thus, this research aims to present the possible differences existing in the qualification and performance of both technological and undergraduate professionals. As for methodology, the investigation was designed based on qualitative research and the main instrument used was the documental analysis of the following documents: Regulation Law of the Profession (Law 7377, September 30 th, and Law 9261, January 10 th, 1996; General National Curriculum Policies to the organization and operation of technological college courses (Resolution CNE/CP 3, December 18th, 2002), the National Catalogue of Technological College Courses as well as the National Curriculum Policies to the Executive Secretarial Course (Resolution $\mathrm{CNE} / \mathrm{CES} \mathrm{n}^{\circ}$ 3/2005, June 23 th, 2005. (in Portuguese: lei de regulamentação da profissão (Lei 7.377, de 30/09/85 e Lei 9.261, de 10/01/96); Diretrizes Curriculares Nacionais Gerais para a organização e o funcionamento dos cursos superiores de tecnologia (Resolução CNE/CP 3, de 18 de dezembro de 2002), Catálogo Nacional de Cursos Superiores de Tecnologia e Diretrizes Curriculares Nacionais para o curso de Secretariado Executivo (Resolução CNE/CES n. 3/2005, de 23 de junho de 2005.) The study shows that the main differences are related to the academic hours in class, the offer of foreign languages as well as the terminology used to entitle such courses. It also demonstrates that the Professional Regulation Law, not foreseeing the existing differences between the two degrees, contributes to the raise of doubts, especially about the performance of these professionals, once both are considered Executive Secretaries.
\end{abstract}

Keywords: College Courses; Technology Degree; Bachelor's Degree; Executive Secretariat Courses; Policies.

Revista de Gestão e Secretariado - GeSec, São Paulo, v. 5, n. 1, p 62-81, jan./abr. 2014. 


\title{
1 INTRODUÇÃO
}

Embora as atividades de secretariado já existam de longa data, como mostra o histórico da profissão ao remetê-la às atividades dos escribas, a regulamentação da profissão ainda é muito recente, datada de 30/09/1985.

Apesar de ser uma profissão considerada nova, muitos avanços na área são percebidos, principalmente no que tange ao delineamento do perfil profissional e à responsabilidade que esse assume frente aos processos de gestão:

\begin{abstract}
Hoje, as organizações demandam profissionais que desempenhem um papel fundamental de assessoria no contexto organizacional, tendo a responsabilidade de participar de gerenciamento de informações, documentos e pessoas, contribuir para a melhoria das relações interpessoais, manifestando dinamismo e flexibilidade, capacidade de empreendimento e automotivação (SANTOS \& CAIMI, 2009, p. 25).
\end{abstract}

A lei de regulamentação confere o registro profissional ao portador de diploma de curso superior em Secretariado, e no contexto atual existem dois graus de formação: o bacharel e o tecnólogo.

Vale ressaltar que o país está vivendo um momento de muito incentivo, por meio das políticas públicas, para a formação de profissionais de nível técnico e tecnológico, aptos a assumirem rapidamente seus postos no mercado de trabalho que se tem mostrado ávido por mão de obra capacitada. Por isso, há bastante estímulo às instituições de ensino para que ofereçam cursos superiores de menor duração.

Assim sendo, ambos os graus sendo de formação superior, concedem ao egresso dos cursos de Secretariado o direito ao Registro Profissional na Delegacia Regional do Trabalho (DRT) ou Superintendência Regional do Trabalho e Emprego (SRTE), uma vez que a profissão ainda não possui um Conselho de Classe.

Porém esse contexto parece ainda não estar muito claro, principalmente para os alunos dos cursos e interessados pela profissão. Os autores da pesquisa, atuando na gestão de um curso superior de tecnologia em Secretariado na modalidade $\mathrm{EaD}$, com polos em praticamente todos os estados do país, atendem com frequência alunos oriundos de diferentes localidades. Eles questionam sobre as diferenças entre os cursos superiores de tecnologia e bacharelado em Secretariado, o que demonstra que ainda existem questionamentos acerca da titulação, bem como das competências e habilidades do profissional de Secretariado egresso dessas formações. 
A partir desse contexto, pretende-se com este artigo, tomando como base a legislação pertinente, contribuir para que alunos e profissionais da área compreendam as especificidades e diferenças entre os cursos superiores de tecnologia e bacharelado em Secretariado.

A pesquisa qualitativa foi a base para o estudo, e o principal instrumento utilizado foi a análise documental dos seguintes documentos: lei de regulamentação da profissão (Lei 7.377, de 30/9/85 e Lei 9.261, de 10/01/96); Diretrizes Curriculares Nacionais Gerais para a organização e o funcionamento dos cursos superiores de tecnologia (Resolução CNE/CP 3, De 18 De Dezembro de 2002), Catálogo Nacional de Cursos Superiores de Tecnologia e Diretrizes Curriculares Nacionais para o curso de Secretariado Executivo (Resolução CNE/CES n. 3/2005, de 23 de junho de 2005.

Serão aqui apresentados os principais aspectos de cada um dos documentos mencionados, e um comparativo sobre as exigências para cada um dos graus de formação superior.

\section{REFERENCIAL TEÓRICO}

Para compreender as discussões eminentes do tema proposto, ou seja, a formação do profissional de Secretariado Executivo em cursos superiores de tecnologia e bacharelado em Secretariado, é preciso analisar a legislação pertinente e que, portanto, constitui a base para organização dos cursos citados.

No Brasil, os documentos norteadores, ou seja, aqueles que determinam como devem ser organizados, pelas Instituições de Ensino Superiores (IES), seus respectivos cursos, são as Diretrizes Curriculares Nacionais, as quais são instituídas pelo Ministério da Educação (MEC) representado pelo Conselho Nacional de Educação (CNE).

De acordo com a Lei de Diretrizes e Base da Educação Nacional (LDB), a lei geral da educação brasileira, que como o próprio nome diz, dita as diretrizes e as bases da organização do sistema educacional, uma Diretriz é um documento norteador. No artigo 53 da respectiva Lei, o qual se refere às atribuições das Instituições de Ensino Superior, é possível perceber como a autonomia e a observação da lei, precisam caminhar juntas:

Art. 53 $^{\circ}$. No exercício de sua autonomia, são asseguradas às universidades, sem prejuízo de outras, as seguintes atribuições:

I - criar, organizar e extinguir, em sua sede, cursos e programas de educação superior previstos nesta Lei, obedecendo às normas gerais da União e, quando for o caso, do respectivo sistema de ensino;

II - fixar os currículos dos seus cursos e programas, observadas as diretrizes gerais pertinentes;

III - estabelecer planos, programas e projetos de pesquisa científica, produção artística e atividades de extensão;

Revista de Gestão e Secretariado - GeSec, São Paulo, v. 5, n. 1, p 62-81, jan./abr. 2014. 


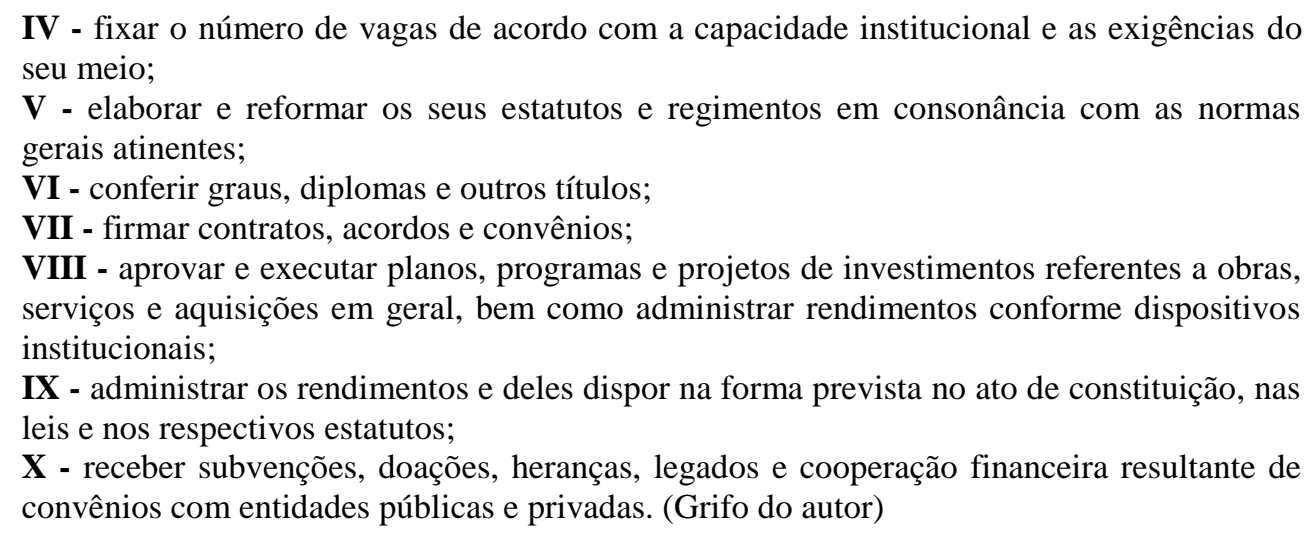

Embora as universidades, faculdades e centros universitários ${ }^{i}$ tenham certa autonomia sobre a organização de seus cursos, respeitando a missão e a filosofia de cada instituição, essa autonomia é sempre pautada em parâmetros mínimos a ser cumpridos, os quais estão presentes nas Diretrizes Curriculares.

É a Diretriz que trata sobre a estrutura mínima que cada curso deve possuir, tanto quanto a organização curricular (disciplinas, estágio, trabalho de conclusão de curso), quanto estrutural (existência de laboratórios específicos), para que seja possível o desenvolvimento das competências e habilidades necessárias para a formação do egresso de acordo com o perfil delimitado para aquela profissão. Em casos de profissões regulamentadas, como é a de Secretariado, a lei de regulamentação da profissão também deve se constituir em fonte de informação e embasamento para organização dos cursos.

A Diretriz Curricular também é um dos documentos que serve de base ao Ministério da Educação para avaliação e reconhecimento dos cursos, a qual é feita a fim de assegurar a qualidade dos cursos que são colocados no mercado.

No caso dos cursos de bacharelado, cada curso possui a sua própria Diretriz. Para o curso de Secretariado Executivo, tem-se a Resolução n. 3, de 23 de junho de 2005.

\subsection{DIRETRIZES CURRICULARES NACIONAIS PARA O CURSO DE GRADUAÇÃO EM SECRETARIADO EXECUTIVO: RESOLUÇÃO N. 3, DE 23 DE JUNHO DE 2005}

A Resolução 3 de 23 de junho de 2005 institui as Diretrizes Curriculares Nacionais para o curso de graduação em Secretariado Executivo, bacharelado, a serem observadas pelas Instituições de Ensino Superior em sua organização curricular: 
Art. $2^{\circ}$ A organização do curso de graduação em Secretariado Executivo, observadas as Diretrizes Curriculares Nacionais e os pareceres desta Câmara, indicará claramente os componentes curriculares, abrangendo o perfil do formando, as competências e habilidades, os conteúdos curriculares e a duração do curso, o regime de oferta, as atividades complementares, o sistema de avaliação, o estágio curricular supervisionado e o trabalho de curso ou de graduação, ambos como componentes opcionais da instituição, sem prejuízo de outros aspectos que tornem consistente o projeto pedagógico.

É possível perceber que a Diretriz permite que alguns aspectos sejam opcionais, ou seja, podem ou não serem instituídos no curso de acordo com os interesses e objetivos da instituição que o organiza, como é o caso das linhas de formação:

$\S 2^{\circ}$ Os projetos pedagógicos do curso de graduação em Secretariado Executivo poderão admitir linhas de formação específicas, nas diversas áreas relacionadas com atividades gerenciais, de assessoramento, de empreendedorismo e de consultoria, contidas no exercício das funções de Secretário Executivo, para melhor atender às necessidades do perfil profissiográfico que o mercado ou a região exigirem.

É por isso que, embora tendo uma Diretriz única, os cursos de Secretariado e Secretariado Executivo que estão no mercado apresentam diferenças entre si. Essas diferenças podem ser percebidas nos seguintes aspectos: nomes das disciplinas, carga horária final do curso, organização por módulo, currículo anual ou semestral, oferta de idiomas, trabalho de conclusão de curso etc.

Todavia, alguns elementos centrais, mesmo que com denominações diferentes, estão presentes em todos os cursos, pois são os fundamentos para o desenvolvimento das habilidades e competências desse profissional.

As competências e habilidades mínimas previstas para o profissional bacharel em Secretariado são contempladas também pela Diretriz e devem ser observadas por todas as instituições. São elas:

Art. $4^{\circ} \mathrm{O}$ curso de graduação em Secretariado Executivo deve possibilitar a formação profissional que revele, pelo menos, as seguintes competências e habilidades:

I - capacidade de articulação de acordo com os níveis de competências fixadas pelas organizações;

II - visão generalista da organização e das peculiares relações hierárquicas e intersetoriais;

III - exercício de funções gerenciais, com sólido domínio sobre planejamento, organização, controle e direção;

IV - utilização do raciocínio lógico, crítico e analítico, operando com valores e estabelecendo relações formais e causais entre fenômenos e situações organizacionais;

$\mathrm{V}$ - habilidade de lidar com modelos inovadores de gestão;

VI - domínio dos recursos de expressão e de comunicação compatíveis com o exercício profissional, inclusive nos processos de negociação e nas comunicações interpessoais ou intergrupais;

VII - receptividade e liderança para o trabalho em equipe, na busca da sinergia;

VIII - adoção de meios alternativos relacionados com a melhoria da qualidade e da produtividade dos serviços, identificando necessidades e equacionando soluções;

IX - gerenciamento de informações, assegurando uniformidade e referencial para diferentes

Revista de Gestão e Secretariado - GeSec, São Paulo, v. 5, n. 1, p 62-81, jan./abr. 2014. 
$\mathrm{X}$ - gestão e assessoria administrativa com base em objetivos e metas departamentais e empresariais;

XI - capacidade de maximização e otimização dos recursos tecnológicos;

XII - eficaz utilização de técnicas secretariais, com renovadas tecnologias, imprimindo segurança, credibilidade e fidelidade no fluxo de informações; e

XIII - iniciativa, criatividade, determinação, vontade de aprender, abertura às mudanças, consciência das implicações e responsabilidades éticas do seu exercício profissional.

Para assegurar o desenvolvimento das habilidades e competências apresentadas, a Diretriz institui os conteúdos básicos, específicos e teórico-práticos que irão compor as grades curriculares de cada curso:

Art. $5^{\circ}$ Os cursos de graduação em Secretariado Executivo deverão contemplar, em seus projetos pedagógicos e em sua organização curricular, os seguintes campos interligados de formação:

I - Conteúdos básicos: estudos relacionados com as ciências sociais, com as ciências jurídicas, com as ciências econômicas e com as ciências da comunicação e da informação;

II - Conteúdos específicos: estudos das técnicas secretariais, da gestão secretarial, da administração e planejamento estratégico nas organizações públicas e privadas, de organização e métodos, de psicologia empresarial, de ética geral e profissional, além do domínio de, pelo menos, uma língua estrangeira e do aprofundamento da língua nacional;

III - Conteúdos teórico-práticos: laboratórios informatizados, com as diversas interligações em rede, estágio curricular supervisionado e atividades complementares, especialmente a abordagem teórico-prática dos sistemas de comunicação, com ênfase em softwares e aplicativos.

É importante observar que os campos apresentados do artigo $5^{\circ}$ não são opcionais, ou seja, todas as instituições que se propuserem a ofertar o curso de bacharelado em Secretariado Executivo, para terem seus projetos aprovados e posteriormente seus cursos reconhecidos, terão obrigatoriamente que manter a estrutura citada nesse artigo, destacando o estágio supervisionado e as atividades complementares como conteúdo curricular obrigatório.

Art. $7^{\circ} \mathrm{O}$ estágio supervisionado é um componente curricular obrigatório, indispensável à consolidação dos desempenhos profissionais desejados inerentes ao perfil do formando, devendo cada instituição, por seu colegiado superior acadêmico, aprovar o correspondente regulamento, com suas diferentes modalidades de operacionalização.

Diferentemente do estágio supervisionado, o trabalho de conclusão de curso é um componente opcional:

Art. 10. O Trabalho de Conclusão de Curso - TCC é um componente curricular opcional da instituição que, se for adotado, poderá ser desenvolvido nas modalidades de monografia, projeto de iniciação científica ou projetos de atividades centrados em áreas teórico-práticas e de formação profissional relacionadas com o curso, na forma disposta em regulamento

próprio.

Revista de Gestão e Secretariado - GeSec, São Paulo, v. 5, n. 1, p 62-81, jan./abr. 2014. 
Mesmo sendo opcional, a inserção do trabalho de conclusão de curso nos currículos dos cursos de bacharelado em Secretariado Executivo, seja na forma de monografia, de artigo, ou mesmo relacionado ao estágio supervisionado, respeitando sempre o regulamento próprio de cada instituição de ensino, é muito bem vista pelo Ministério da Educação e pelos docentes da área, pois é uma forma de fomentar a pesquisa na área secretarial e contribuir para o desenvolvimento contínuo da profissão.

Além da Diretriz de cada curso, existem também pareceres e resoluções que tratam de assuntos complementares, como é o caso da carga horária mínima exigida para os cursos. No caso dos cursos de bacharelado é a Resolução n. 2, de 18 de junho de 2007 que institui que os cursos de Secretariado Executivo precisam ter, no mínimo, 2.400 horas.

\subsection{DIRETRIZES CURRICULARES NACIONAIS GERAIS PARA A ORGANIZAÇÃO E O FUNCIONAMENTO DOS CURSOS SUPERIORES DE TECNOLOGIA. RESOLUÇÃO CNE/CP 3, DE 18 DE DEZEMBRO DE 2002.}

As Diretrizes Curriculares para os cursos superiores de Tecnologia foram instituídas em 2002, e diferentemente dos cursos de bacharelado que possuem uma diretriz específica para cada curso, é única para todos os cursos tecnológicos.

Como embasamento para o desenvolvimento dos currículos e conteúdos mínimos a ser instituídos, a Diretriz apresenta os pressupostos a seguir:

\footnotetext{
Art. $2^{\circ}$ Os cursos de educação profissional de nível tecnológico serão designados como cursos superiores de tecnologia e deverão:

I - incentivar o desenvolvimento da capacidade empreendedora e da compreensão do processo tecnológico, em suas causas e efeitos;

II - incentivar a produção e a inovação científico-tecnológica, e suas respectivas aplicações no mundo do trabalho;

III - desenvolver competências profissionais tecnológicas, gerais e específicas, para a gestão de processos e a produção de bens e serviços;

IV - propiciar a compreensão e a avaliação dos impactos sociais, econômicos e ambientais resultantes da produção, gestão e incorporação de novas tecnologias;

$\mathrm{V}$ - promover a capacidade de continuar aprendendo e de acompanhar as mudanças nas condições de trabalho, bem como propiciar o prosseguimento de estudos em cursos de pósgraduação;

VI - adotar a flexibilidade, a interdisciplinaridade, a contextualização e a atualização permanente dos cursos e seus currículos;

VII - garantir a identidade do perfil profissional de conclusão de curso e da respectiva organização curricular.
}

A Diretriz também determina que os critérios para o planejamento e a organização dos cursos superiores de tecnologia devem ser os seguintes:

Revista de Gestão e Secretariado - GeSec, São Paulo, v. 5, n. 1, p 62-81, jan./abr. 2014. 
I - o atendimento às demandas dos cidadãos, do mercado de trabalho e da sociedade;

II - a conciliação das demandas identificadas com a vocação da instituição de ensino e as suas reais condições de viabilização;

III - a identificação de perfis profissionais próprios para cada curso, em função das demandas e em sintonia com as políticas de promoção do desenvolvimento sustentável do País (Art. $3^{\circ}$ ).

Ou seja, os cursos precisam estar alinhados às necessidades do mercado de trabalho e às condições das instituições que os oferecem.

A mesma Diretriz diz também que a organização curricular dos cursos superiores de Tecnologia deverá contemplar o desenvolvimento de competências profissionais a ser formuladas em consonância com o perfil profissional de conclusão do curso, o qual define a sua identidade e caracteriza o compromisso ético da instituição com os seus alunos e a sociedade:

$\S 1^{\circ}$ A organização curricular compreenderá as competências profissionais tecnológicas, gerais e específicas, incluindo os fundamentos científicos e humanísticos necessários ao desempenho profissional do graduado em tecnologia.

$\S 2^{\circ}$ Quando o perfil profissional de conclusão e a organização curricular incluírem competências profissionais de distintas áreas, o curso deverá ser classificado na área profissional predominante (Art. $6^{\circ}$ ).

Diferentemente das Diretrizes para os cursos de Bacharelado, que apresentam claramente as competências esperadas, no caso dos cursos de Tecnologia, há outro documento que determina o que deverá conter em cada curso: O Catálogo Nacional de Cursos Superiores de Tecnologia.

O Catálogo Nacional dos Cursos Superiores de Tecnologia foi lançado em 2006 e está organizado por eixos. Além de apresentar informações sobre o perfil do tecnólogo que se formará em cada um dos cursos, também apresenta a carga horária mínima e a infraestrutura recomendada para cada curso, tornando-se referência para estudantes, educadores, instituições de ensino tecnológico e público em geral. Serve de base também para o Exame Nacional de Desempenho dos Estudantes (Enade) e para os processos de regulação e supervisão da educação tecnológica. "O catálogo organiza e orienta a oferta de cursos superiores de tecnologia, inspirado nas diretrizes curriculares nacionais e em sintonia com a dinâmica do setor produtivo e as expectativas da sociedade. Em função do catálogo, a partir de 2007 foi possível aplicar o Enade em alunos de cursos superiores de tecnologia" (Ministério da Educação e Cultura, 2010, p. 8).

No Catálogo de Cursos Superiores de Tecnologia o curso de Secretariado faz parte do eixo Gestão de Negócios. Nesse eixo estão os cursos que atendem às seguintes finalidades:

Revista de Gestão e Secretariado - GeSec, São Paulo, v. 5, n. 1, p 62-81, jan./abr. 2014. 
Compreende tecnologias associadas aos instrumentos, técnicas e estratégias utilizadas na busca da qualidade, produtividade e competitividade das organizações. Abrange ações de planejamento, avaliação e gerenciamento de pessoas e processos referentes a negócios e serviços presentes em organizações públicas ou privadas, de todos os portes e ramos de atuação. Este eixo caracteriza-se pelas tecnologias organizacionais, viabilidade econômica, técnicas de comercialização, ferramentas de informática, estratégias de marketing, logística, finanças, relações interpessoais, legislação e ética. (2010 p. 17).

Fazem parte desse eixo os seguintes cursos: Comércio Exterior, Gestão Comercial, Gestão da Qualidade, Gestão de Cooperativas, Gestão de Recursos Humanos, Gestão Financeira, Gestão Pública, Logística, Marketing, Negócios Imobiliários Processos Gerenciais e Secretariado.

De acordo com o mesmo documento, as habilidades e competências do egresso do curso de Tecnologia em secretariado são as seguintes:

O tecnólogo em Secretariado planeja e organiza os serviços de secretaria de centros decisórios de uma instituição. Aplicando conceitos e ferramentas tecnológicas específicas de assessoramento, de forma a otimizar os processos vinculados a suas atividades, este profissional assessora executivos, diretores e suas respectivas equipes, planeja, organiza, implanta e executa atividades e metas da área, eventos, serviços protocolares, viagens, relações com clientes e fornecedores, comunicação e redação de textos técnicos, além de gerenciar informações. (2010, p. 40).

Quanto à infraestrutura recomendada, o catálogo apresenta apenas dois itens: Biblioteca com acervo específico e atualizado Laboratório de informática com programas específicos. Já com referência à carga horária mínima, determina-se que o curso de Secretariado tenha no mínimo 1.600 horas.

Também é importante destacar o que diz a Diretriz da Resolução CNE/CP 3 (2002), a respeito das profissões regulamentadas, como é o caso do curso de Secretariado:

Art. 10. As instituições de ensino, ao elaborarem os seus planos ou projetos pedagógicos dos cursos superiores de tecnologia, sem prejuízo do respectivo perfil profissional de conclusão identificado, deverão considerar as atribuições privativas ou exclusivas das profissões regulamentadas por lei.

Ou seja, no processo de elaboração dos projetos de curso, é fundamental que as IES planejem a formação dos profissionais em Tecnologia com base nas atribuições profissionais consideradas na Lei de regulamentação, no caso do Secretariado a Lei n. 7.377 de 30 de setembro de 1995 e pela Lei n. 9.261 de 10 de outubro de 1996, conforme explicitadas no item a seguir.

2.3 LEI DE REGULAMENTAÇÃO DA PROFISSÃO: LEI 7377, DE 30/09/85 E LEI

Revista de Gestão e Secretariado - GeSec, São Paulo, v. 5, n. 1, p 62-81, jan./abr. 2014. 
9261, DE 10/01/96

A lei de regulamentação da profissão, que teve sua única alteração no ano de 1996, prevê dois níveis de formação para os profissionais de Secretariado: A formação em curso superior e o técnico em Secretariado:

Art.2‥ Para os efeitos desta Lei, é considerado:

I - Secretário Executivo

a) o profissional diplomado no Brasil por curso superior de Secretariado, reconhecido na forma de Lei, ou diplomado no exterior por curso de Secretariado, cujo diploma seja revalidado no Brasil, na forma de Lei.

b) o portador de qualquer diploma de nível superior que, na data de vigência desta Lei, houver comprovado, através de declarações de empregadores, o exercício efetivo, durante pelo menos trinta e seis meses, das atribuições mencionados no Art. $4^{\circ}$. desta Lei.

II - Técnico em Secretariado

a) o profissional portador de certificado de conclusão de curso de Secretariado em nível de $2^{\circ}$. Grau;

b) portador de certificado de conclusão do $2^{\circ}$. grau que, na data de início da vigência desta Lei, houver comprovado, através de declarações de empregadores, o exercício efetivo, durante pelo menos trinta e seis meses, das atribuições mencionados no Art. $5^{\circ}$. desta Lei.

Sobre as habilidades e competências inerentes ao exercício desse profissional, aqui se tratando daquele formado em nível superior, a lei diz o seguinte:

Art.4‥ São atribuições do Secretário Executivo:

I - planejamento, organização e direção de serviços de secretaria; II - assistência e assessoramento direto a executivos; III - coleta de informações para a consecução de objetivos e metas de empresas; IV - redação de textos profissionais especializados, inclusive em idioma estrangeiro; V - interpretação e sintetização de textos e documentos; VI - taquigrafia de ditados, discursos, conferências, palestras de explanações, inclusive em idioma estrangeiro; VII - versão e tradução em idioma estrangeiro, para atender às necessidades de comunicação da empresa; VIII - registro e distribuição de expediente e outras tarefas correlatas; IX - orientação da avaliação e seleção da correspondência para fins de encaminhamento a chefia;

$\mathrm{X}$ - conhecimentos protocolares.

(grifo do autor).

Vale aqui destacar o que diz a lei sobre a exigência de idioma estrangeiro na formação superior do Secretariado Executivo, fato que está perfeitamente alinhado às exigências que o mercado de trabalho apresenta para a atuação deste profissional, mas nem sempre presente nas grades curriculares, principalmente dos cursos de Tecnologia, ou pelo menos não com uma carga horária que propicie efetivamente o domínio de um idioma estrangeiro. 
Também é salutar destacar que a lei não trata especificamente sobre o tecnólogo em Secretariado, corroborando para o surgimento de dúvidas sobre a essência de cada formação.

Todavia, tendo em vista o expansivo crescimento dos cursos de Tecnologia em Secretariado, em 2008, a Federação Nacional das Secretarias e Secretários (Fenassec) promoveu o IV Fórum Nacional que aconteceu na cidade de Brasília, como parte do XVI Consec e V Simisec, e publicou em sua página o documento "Resoluções do IV Fórum Nacional de Debates sobre Competências Profissionais: Níveis de Atuação".

Tal documento apresenta uma organização da categoria secretarial em três níveis propostos de atuação e de formação:

- Técnico em Secretariado - nível operacional;

- Tecnólogo em Secretariado - nível tático;

- Bacharel em Secretariado Executivo - nível estratégico.

No Quadro 1, é apresentada, de forma sintética, a análise das competências profissionais dos tecnólogos e bacharéis em Secretariado, com base nas informações originadas dos debates do IV Fórum de Nacional sobre competências profissionais dos Secretários nos dois níveis de atuação.

Quadro 1 - Análise das Competências do Tecnólogo e do bacharel em Secretariado a partir do IV Fórum Nacional de Secretariado

\begin{tabular}{|c|c|}
\hline TECNÓLOGO EM SECRETARIADO & BACHAREL EM SECRETARIADO EXECUTIVO \\
\hline $\begin{array}{l}\text { Nível Tático } \\
\text { Grupo - profissionais que atuem em médias e } \\
\text { grandes empresas. } \\
\text { Competências: } \\
\text { 1. deter sólidos domínios tecnológicos específicos } \\
\text { de seu campo de atuação; } \\
\text { 2. assessorar na gestão de processos } \\
\text { administrativos na gestão pública e privada; } \\
\text { 3. assessorar os centros decisórios e equipes; } \\
\text { 4. dominar os diferentes meios de comunicação no } \\
\text { seu idioma nativo e outros idiomas; } \\
\text { 5. ser articulador em negociações que precedam à } \\
\text { tomada de decisões. }\end{array}$ & $\begin{array}{l}\text { Nível Estratégico } \\
\text { Grupo - profissionais que atuem em médias e grandes } \\
\text { empresas. } \\
\text { Competências: } \\
\text { 1. capacidade de análise, interpretação e articulação de } \\
\text { conceitos da administração pública e privada; } \\
\text { 2. ter postura reflexiva e visão crítica que fomente a capacidade } \\
\text { de gerir e administrar processos e pessoas (observados os níveis } \\
\text { graduais de tomada de decisões); } \\
\text { 3. atuar nos três níveis do comportamento organizacional: } \\
\text { micro, meso e macro-organizacional. }\end{array}$ \\
\hline
\end{tabular}

Fonte: Elaboração do autor a partir da resolução do IV Fórum Nacional de debates sobre competências profissionais: níveis de atuação (Fenassec, n.d). 
Todavia, como atualmente o registro profissional como Secretário Executivo é atribuído tanto aos profissionais egressos dos cursos superiores de Tecnologia, quanto dos cursos de Bacharelado em Secretariado, considerando que a legislação considera Secretário Executivo aquele formado em curso superior, sem fazer distinção entre os graus, abrem-se possibilidades para a existência de lacunas e interpretações sobre o perfil profissional que se espera de tais formações, constantemente percebidas em editais para vagas de emprego ou mesmo de concursos públicos. Isso leva muitos alunos ao seguinte questionamento: O que deve ser então considerado no ato de uma contratação: o registro profissional ou diploma de formação? Talvez ainda não tenhamos uma resposta objetiva para tal pergunta.

\section{METODOLOGIA}

Esta pesquisa se caracterizou como um estudo de natureza qualitativa de caráter explicativoexploratório. Exploratório porque pretende gerar propostas para futuras pesquisas e explicativo pelo interesse em apresentar as diferenças quanto ao entendimento legal da formação bacharel e tecnólogo do curso de Secretariado.

Como metodologia, adotou-se uma estratégia de pesquisa documental, tomando como fonte de dados os principais documentos oficiais que tratam da regulamentação da profissão, a LDBN e as Resoluções sobre o funcionamento dos cursos superiores. Dessa forma, os documentos selecionados compreendem:

$\checkmark$ Lei n. 7.377, de 30 de setembro de 1985 que dispõe sobre o Exercício da Profissão de Secretário, e dá outras Providências;

$\checkmark$ Lei 9.261, de 10 de janeiro de 1996, que altera a redação dos incisos I e II do art. $2^{\circ}$, o caput do art. $3^{\circ}$, o inciso VI do art. $4^{\circ}$ e o parágrafo único do art. $6^{\circ}$ da Lei n. 7.377 de 30 de setembro de 1985;

$\checkmark$ Lei n. 9.394, de 20 de dezembro de 1996, que estabelece as Diretrizes e Bases da Educação Nacional;

$\checkmark$ Catálogo Nacional dos Cursos Superiores de Tecnologia, Ministério da Educação e Cultura;

$\checkmark$ Resolução CNE/CP 3, de 18 e dezembro de 2002, sobre as Diretrizes curriculares nacionais gerais para a organização e o funcionamento dos cursos superiores de tecnologia; 
$\checkmark$ Resolução n. 3, de 23 de junho de 2005. (2005). Diretrizes curriculares nacionais para o curso de graduação em secretariado executivo. Diário Oficial da União. Brasília, DF: Ministério da Educação e Cultura;

$\checkmark$ Resolução n. 2, de 18 de junho de 2007, que dispõe sobre carga horária mínima e procedimentos relativos à integralização e duração dos cursos de graduação, bacharelados, na modalidade presencial.

Após a separação dos documentos, passou-se ao próximo passo da pesquisa, que foi a análise dos dados. Nessa fase, utilizou-se o método análise de conteúdo, que segundo Moraes (1999) possibilita o atendimento de inúmeras necessidades de pesquisadores envolvidos na análise de dados de comunicação, especialmente aqueles voltados a uma abordagem qualitativa.

\section{ANÁLISE DOS RESULTADOS}

Uma vez apresentados os principais aspectos das diretrizes dos cursos de Tecnologia e Bacharelado em Secretariado Executivo e Secretariado, e a lei de regulamentação da profisssão, é possível delinear as principais diferenças entre um grau e outro.

A lei de regulamentação não faz menção ao bacharelado ou tecnológico, apenas se refere ao profissional diplomado no Brasil por curso superior de Secretariado, reconhecido na forma de Lei, ou diplomado no exterior por curso de Secretariado, cujo diploma seja revalidado no Brasil, na forma de Lei.

Assim sendo, os egressos dos cursos de Tecnologia em Secretariado podem solicitar seu registro profissional junto às Delegacias Regionais do Trabalho (DRT) ou Superintendência Regional do Trabalho e Emprego (SRTE), como Secretário Executivo ou Secretária Executiva, sem distinção do grau de formação.

Aqui se pode afirmar que o Secretariado, por ser uma profissão regulamentada, está à frente de muitos outros cursos de tecnologia, cujos projetos de lei sobre a regulamentação do profissional “tecnólogo" estão em pauta, conforme consta no projeto de Lei PL n. 2.245/07, que tramita junto à câmara nacional dos deputados, que regulamenta a profissão de Tecnólogo e dá outras providências.

No caso do Secretário, não existe um registro como tecnólogo, mas esse é reconhecido como Secretário Executivo, independentemente de o seu grau de conclusão ser bacharel ou tecnólogo.

Esse fato faz com que surjam outras indagações por parte daqueles que procuram por essa 
formação, como, por exemplo, o fato de o curso de bacharelado ser denominado como Secretariado Executivo, ou Secretariado Executivo Bilíngue, ou até mesmo Secretariado Executivo Trilíngue, e o Tecnólogo apenas como Secretariado, já que o registro profissional não faz distinção.

A variação na denominação dos cursos de bacharelado pode ser entendida como estando diretamente relacionada à oferta de línguas estrangeiras, lembrando que há a obrigatoriedade da oferta de pelo menos um idioma estrangeiro, como previsto no artigo $5^{\circ}$ da Diretriz, que trata sobre os conteúdos específicos que deverão compor o projeto pedagógico dos cursos de bacharelado em Secretariado Executivo.

A oferta de mais de um idioma estrangeiro, e a autonomia que as instituições têm sobre a organização dos seus currículos, possibilitou que fossem agregados aos nomes dos seus cursos também a representação das línguas estrangeiras que oferecem. As denominações Secretário Executivo; Secretário Executivo Bilíngue e Secretário Executivo Trilíngue estão previstos na Classificação Brasileira de Ocupações ${ }^{\mathrm{ii}}$.

Já no caso dos cursos de Tecnologia, embora exista a oferta de disciplinas de idiomas estrangeiros, em grande parte dos cursos ela está restrita ao inglês e espanhol instrumental, justamente pela restrição da carga horária do curso, geralmente distribuída em dois anos quando no bacharelado são no mínimo três anos, embora cada instituição tenha autonomia para inserir disciplinas, bem como para ampliar o número de horas de seus cursos.

Se a instituição decidir por ampliar a carga horária de idiomas, sem aumentar o número de horas do curso, certamente conteúdos considerados básicos e obrigatórios para a formação do profissional, devido ao pouco tempo que se tem, poderiam ser omitidos ou trabalhados de forma acelerada no âmbito das disciplinas.

Embora, como já foi dito, as instituições tenham autonomia para ampliar o número de horas, grande parte delas, principalmente as privadas, não costumam ultrapassar muito a carga mínima prevista, até mesmo pela questão do tempo de integralização do currículo, ou seja, quanto tempo o aluno precisará para concluir o curso. O tempo mínimo para conclusão de um curso de bacharelado é de três anos, quando o de tecnologia é apenas de dois anos, como já foi dito, o que vai ao encontro da necessidade do mercado de formar rapidamente profissionais capacitados para inserção imediata nos postos de trabalho.

Quanto ao fato de o curso de Tecnologia ser denominado apenas como Secretariado é em cumprimento ao que determina o Catálogo Nacional de Cursos Superiores, que prevê apenas a denominação "Secretariado", item que constitui o instrumento de avaliação dos cursos, ou seja, a

Revista de Gestão e Secretariado - GeSec, São Paulo, v. 5, n. 1, p 62-81, jan./abr. 2014. 
denominação do curso deve estar de acordo com o previsto pelo catálogo, portanto, apenas "Secretariado".

Outra diferença percebida entre os graus de formação do profissional de Secretariado Executivo é quanto à obrigatoriedade do estágio supervisionado. O estágio só é obrigatório para o curso de bacharelado. Respeitando a autonomia das instituições, ele pode sim ser ofertado nos cursos de tecnologia, mas é uma decisão das IES, e não uma obrigatoriedade, como no caso do bacharelado.

O quadro a seguir apresenta as principais diferenças entre os cursos de Tecnologia e Bacharelado em Secretariado com base nas diretrizes pertinentes:

Quadro 2 - Diferenças da formação em tecnologia e bacharel dos cursos superiores em Secretariado.

\begin{tabular}{|c|c|c|c|}
\hline & $\begin{array}{l}\text { BACHARELADO } \\
\text { (DIRETRIZES) }\end{array}$ & $\begin{array}{l}\text { TECNOLÓGICO } \\
\text { (DIRETRIZES) }\end{array}$ & $\begin{array}{c}\text { LEI DE } \\
\text { REGULAMENTAÇÃO }\end{array}$ \\
\hline Estágio Supervisionado & Obrigatório & Opcional & Não menciona \\
\hline $\begin{array}{c}\text { Trabalho de Conclusão } \\
\text { de Curso }\end{array}$ & Opcional & Opcional & Não menciona \\
\hline $\begin{array}{c}\text { Atividades } \\
\text { Complementares }\end{array}$ & Obrigatório & Não menciona & Não menciona \\
\hline Idiomas Estrangeiros & $\begin{array}{l}\text { Obrigatório ao menos um } \\
\text { idioma estrangeiro }\end{array}$ & Não menciona & $\begin{array}{c}\text { Art. } 4^{o} \text {. São atribuições do } \\
\text { Secretário Executivo: } \\
\text { - redação de textos profissionais } \\
\text { especializados, inclusive em } \\
\text { idioma estrangeiro; }\end{array}$ \\
\hline Nomenclatura & $\begin{array}{c}\text { Secretariado Executivo, } \\
\text { Secretariado Executivo } \\
\text { Bilíngue, Secretariado } \\
\text { Executivo Trilíngue }\end{array}$ & Secretariado & $\begin{array}{l}\text { Secretário Executivo é todo } \\
\text { Profissional formado em curso } \\
\text { Superior de Secretariado. }\end{array}$ \\
\hline Carga horária & Mínimo: $2.400 \mathrm{~h}$ & Mínimo: $1.600 \mathrm{~h}$ & Não menciona \\
\hline
\end{tabular}

Fonte: Elaboração própria com base na interpretação das Diretrizes Curriculares dos cursos de Bacharelado e Tecnologia e Catálogo Nacional dos Cursos Superiores de Tecnologia.

\section{CONSIDERAÇÕES FINAIS}

Revista de Gestão e Secretariado - GeSec, São Paulo, v. 5, n. 1, p 62-81, jan./abr. 2014. 
É possível entender que talvez determinar as diferenças entre as formações nos graus de tecnólogo e bacharel em Secretariado não seja uma tarefa fácil, uma vez que essa discussão ainda está em processo. Embora existam importantes apontamentos a partir justamente do contexto social que fez emergir a categoria dos profissionais tecnólogos, ainda não é possível responder a todos os questionamentos que surgem, principalmente sobre a atuação desses profissionais.

Nesse breve estudo sobre o que determinam as diretrizes curriculares e a lei de regulamentação da profissão foi possível levantar os principais pontos que diferem um grau de formação de outro. Da mesma forma, podem-se também perceber algumas lacunas, como por exemplo, sobre os idiomas estrangeiros, que são exigidos pela lei de regulamentação, mas não estão explícitos nas diretrizes para os cursos superiores de Tecnologia. Se de fato essa é uma competência a ser desenvolvida pelo tecnólogo em Secretariado, entende-se que seria pertinente um alinhamento das informações, pois embora a diretriz em seu art. 10 afirme que as instituições de ensino, ao elaborarem os seus planos ou projetos pedagógicos dos cursos superiores de tecnologia, deverão considerar as atribuições privativas ou exclusivas das profissões regulamentadas por lei, se as demais competências estão previstas em documento próprio, nesse caso, o Catálogo Nacional de Cursos Superiores de Tecnologia, não há porque omitir tal informação.

Acredita-se que esse estudo possa suscitar o surgimento de novas pesquisas sobre o tema, suscitando também a atualização da lei de regulamentação, a fim de que aborde de forma mais abrangente as questões específicas de cada formação, e principalmente, a questão do registro profissional para os diferentes graus.

Sabe-se também que a profissão está em constante luta pela criação do Conselho de Classe, fato que certamente contribuirá para a resolução desta e de outras questões eminentes da atuação dos Secretários e Secretárias Executivas.

\section{REFERÊNCIAS}


Fenassec (n.d). Resoluções do IV Fórum Nacional de debates sobre competências profissionais: níveis de atuação. Recuperado em 12 agosto, 2013 de www.fenassec.com.br/pdf/artigos_forum_debates_resolucoes_4.pdf

Lei n. 7.377, de 30 de setembro de 1985. (1985). Dispõe sobre o Exercício da Profissão de Secretário, e dá outras Providências. Diário Oficial da União. Brasília, DF: Ministério da Educação e Cultura.

Lei 9.261, de 10 de janeiro de 1996. (1996). Altera a redação dos incisos I e II do art. $2^{\circ}$, o caput do art. $3^{\circ}$, o inciso VI do art. $4^{\circ}$ e o parágrafo único do art. $6^{\circ}$ da Lei $n^{\circ} 7.377$ de 30 de setembro de 1985. Diário Oficial da União. Brasília, DF: Ministério da Educação e Cultura.

Lei n. 9.394, de 20 de dezembro de 1996. (1996). Estabelece as Diretrizes e Bases da Educação Nacional. Diário Oficial da União. Brasília, DF: Ministério da Educação e Cultura.

Ministério da Educação e Cultura. (n.d). Catálogo Nacional dos Cursos Superiores de Tecnologia. Recuperado em 10 agosto, 2013, de http://portal.mec.gov.br/.

Ministério da Educação e Cultura. Qual é a diferença entre faculdades, centros universitários e $\begin{array}{llllll}\text { universidades? } & \text { Recuperado em } & 30 & \text { julho, } & 2013 & \text { de }\end{array}$ http://portal.mec.gov.br/index.php?Itemid=86\&id=116\&option=com_content\&view=article.

Moraes, Roque. (1999). Análise de conteúdo. Revista Educação, Porto Alegre, vol. 22, n. 37, pp. 7 32.

Neves, José Luis. (1996). Pesquisa Qualitativa - Características, usos e possibilidades. Caderno de pesquisas em administração, São Paulo, vol. 1, n. 3. Recuperado em 30 jul., 2013 de http://www.unisc.br/portal/upload/com_arquivo/pesquisa_qualitativa_caracteristicas usos_e_possibilidades.pdf

Resolução CNE/CP 3, de 18 e dezembro de 2002. (2002). Diretrizes curriculares nacionais gerais para a organização e o funcionamento dos cursos superiores de tecnologia. Publicada no Diário Oficial da União de 23 de dezembro de 2002, Seção 1, p. 162. Brasília, DF: Ministério da Educação e Cultura.

Resolução n. 3, de 23 de junho de 2005. (2005). Diretrizes curriculares nacionais para o curso de graduação em Secretariado Executivo. Diário Oficial da União. Brasília, DF: Ministério da Educação e Cultura.

Resolução n. 2, de 18 de junho de 2007. (2007). Dispõe sobre carga horária mínima e procedimentos relativos à integralização e duração dos cursos de graduação, bacharelados, na modalidade presencial. Diário Oficial da União. Brasília: DF, 19 de junho de 2007, Seção 1, p. 6.

Revista de Gestão e Secretariado - GeSec, São Paulo, v. 5, n. 1, p 62-81, jan./abr. 2014. 
Projeto de Lei n. 2245/07 (n.d). Regulamenta a profissão de Tecnólogo e dá outras providências. Recuperado em $10 \quad$ ago., $2013, \quad$ de http://www.camara.gov.br/proposicoesWeb/prop_mostrarintegra?codteor=514249\&filename=PL $+2245 / 2007$.

Santos, Cássia Viviane dos \& CAIMI, Flávia Eloísa. (2009) Secretário Executivo: formação, atribuições e desafios profissionais. In: Durante, Giareta Daniela; Favero, Altair Alberto (orgs.). Gestão Secretarial: formação e atuação profissional. Passo Fundo: Ed. Universidade de Passo Fundo.

I De acordo com o Decreto 5.773/06, as instituições de educação superior, de acordo com sua organização e respectivas prerrogativas acadêmicas, são credenciadas como: I I - faculdades; II - centros universitários; e III - universidades. As instituições são credenciadas originalmente como faculdades. O credenciamento como universidade ou centro universitário, com as consequentes prerrogativas de autonomia, depende do credenciamento específico de instituição já credenciada, em funcionamento regular e com padrão satisfatório de qualidade. Recuperado em $9 \quad$ ago., $2013 \quad$ de http://portal.mec.gov.br/index.php?Itemid=86\&id=116\&option=com_content\&view=article

ii CBO - Cadastro Brasileiro de Ocupações. A Classificação Brasileira de Ocupações - CBO, instituída por portaria ministerial n. 397, de 9 de outubro de 2002, tem por finalidade a identificação das ocupações no mercado de trabalho, para fins classificatórios junto aos registros administrativos e domiciliares. Os efeitos de uniformização pretendida pela Classificação Brasileira de Ocupações são de ordem administrativa e não se estendem as relações de trabalho. Já a regulamentação da profissão, diferentemente da CBO é realizada por meio de lei, cuja apreciação é feita pelo Congresso Nacional, por meio de seus Deputados e Senadores, e levada à sanção do presidente da República. Recuperado em 12 ago., 2013 de http://www.mtecbo.gov.br/cbosite/pages/home.jsf

Revista de Gestão e Secretariado - GeSec, São Paulo, v. 5, n. 1, p 62-81, jan./abr. 2014. 